\title{
The 'Harmonizing Optimal Strategy for Treatment of coronary artery stenosis - sAfety \& effectiveneSS of drug-elUting stents \& antiplatelet REgimen' (HOST-ASSURE) trial: study protocol for a randomized controlled trial
}

Kyung Woo Park', Byoung-Eun Park², Si-Hyuck Kang ${ }^{1}$, Jin-Joo Park', Seung-Pyo Lee', Kwang Soo Cha ${ }^{3}$, Jay Young Rhew ${ }^{4}$, Hui-Kyoung Jeon ${ }^{5}$, Eun Seok Shin ${ }^{6}$, Ju Hyeon Oh', Myung-Ho Jeong ${ }^{8}$, Sanghyun Kim', Kyung-Kuk Hwang ${ }^{10}$, Jung-Han Yoon ${ }^{11}$, Sung Yun Lee ${ }^{12}$, Tae-Ho Park ${ }^{13}$, Keon Woong Moon ${ }^{14}$, Hyuck-Moon Kwon ${ }^{15}$, In-Ho Chae ${ }^{16^{*}}$ and Hyo-Soo Kim ${ }^{1 *}$, for On behalf of the HOST investigators

\begin{abstract}
Background: Second-generation drug-eluting stents (DES) have raised the bar of clinical performance. These stents are mostly made from cobalt chromium alloy. A newer generation DES has been developed from platinum chromium alloy, but clinical data regarding the efficacy and safety of the platinum chromium-based everolimus-eluting stent (PtCrEES) is limited, with no comparison data against the cobalt chromium-based zotarolimus-eluting stent (CoCr-ZES). In addition, an antiplatelet regimen is an integral component of medical therapy after percutaneous coronary intervention (PCI). A 1-week duration of doubling the dose of clopidogrel (double-dose antiplatelet therapy (DDAT)) was shown to improve outcome at 1 month compared with conventional dose in acute coronary syndrome (ACS) patients undergoing PCl. However in Asia, including Korea, the addition of cilostazol (triplet antiplatelet therapy (TAT)) is used more commonly than doubling the dose of clopidogrel in high-risk patients.
\end{abstract}

Methods: In the 'Harmonizing Optimal Strategy for Treatment of coronary artery stenosis - sAfety \& effectiveneSS of drug-elUting stents \& antiplatelet REgimen' (HOST-ASSURE) trial, approximately 3,750 patients are being prospectively and randomly assigned in a $2 \times 2$ factorial design according to the type of stent (PtCr-EES vs CoCrZES) and antiplatelet regimen (TAT vs DDAT). The first primary endpoint is target lesion failure at 1 year for the stent comparison, and the second primary endpoint is net clinical outcome at 1 month for comparison of antiplatelet therapy regimen.

Discussion: The HOST-ASSURE trial is the largest study yet performed to directly compare the efficacy and safety of the PtCr-EES versus CoCr-ZES in an 'all-comers' population. In addition, this study will also compare the clinical outcome of TAT versus DDAT for 1-month post PCl.

Trial registration: ClincalTrials.gov number NCT01267734.

Keywords: Cilostazol, cobalt chromium, coronary heart disease, everolimus-eluting stent, platinum chromium, zotarolimus-eluting stent

\footnotetext{
* Correspondence: inchae@snu.ac.kr; hyosoo@snu.ac.kr

'Department of Internal Medicine, Cardiovascular Center, Seoul National University Hospital, 101 Daehang-no, Seoul 110-744, South Korea

${ }^{16}$ Seoul National University Bundang Hospital, Seongnam, South Korea

Full list of author information is available at the end of the article
} 


\section{Background}

Various second-generation drug-eluting stents (DES) have been developed in the hopes of improving both efficacy and safety compared with first-generation DES. Cumulative evidence is building suggesting that compared with the paclitaxel-eluting stent, the second-generation everolimus-eluting stent (EES; Xience V, Abbott Vascular, Santa Clara, CA, USA, Promus, Boston Scientific, Natick, MA, USA) is more effective and safe [1-3], and compared with the sirolimus-eluting stent, it has similar efficacy with a trend toward better safety [4-6]. The next addition to the second-generation DES market has been the zotarolimuseluting stent (ZES; Resolute, Medtronic, Minneapolis, MN, USA), which showed equivalent outcome compared with the EES in the RESOLUTE All-Comers randomized trial [7]. Both EES and ZES are based on a cobalt chromium alloy stent. Most recently, a newly developed stent alloy, the platinum chromium alloy, was incorporated with everolimus to create the platinum chromium-based EES (PtCr-EES), the Promus Element stent (Boston Scientific, Natick, MA, USA). There are limited data on the clinical efficacy and safety of the PtCr-EES with only one modestly sized randomized trial that compared it against the cobalt chromium-based EES in a select group of patients and lesions [8]. In the current study, the PtCr-EES will be compared against the cobalt chromium-based ZES (CoCrZES) in a larger scale study with a broader all-comers population.

In addition, antiplatelet regimen is an integral component of medical therapy after percutaneous coronary intervention (PCI). In particular, inhibition of platelet reactivity in the first month post PCI is known to be critical in preventing thrombotic events, since higher on-treatment platelet reactivity is reported to be associated with higher risk of hard endpoints [9-12]. In the CURRENT-OASIS 7 trial, a 1-week duration of doubling the dose of clopidogrel was shown to improve outcome at 1 month compared with conventional dose in acute coronary syndrome (ACS) patients undergoing PCI [13]. In Asia including Korea, the addition of cilostazol as a third antiplatelet agent is used more commonly than doubling the dose of clopidogrel in high-risk patients. However, there has been no large-scale comparison of triple antiplatelet therapy (TAT) versus double-dose clopidogrel antiplatelet therapy (DDAT) to date.

\section{Methods}

\section{Study objectives and hypotheses}

The primary objective of the present study is to compare the efficacy and safety of coronary stenting with the PtCr-EES compared with the CoCr-ZES in the treatment of coronary stenosis, and to evaluate the efficacy and safety of a 1 month duration of TAT consisting of aspirin, clopidogrel $75 \mathrm{mg}$, and cilostazol $200 \mathrm{mg}$ versus DDAT consisting of aspirin and clopidogrel $150 \mathrm{mg}$. The working hypothesis of this trial is that PtCr-EES is noninferior to CoCr-ZES in prevention of target lesion failure (TLF) at 1-year post PCI, and TAT is non-inferior to DDAT regarding net clinical outcome, defined as a composite of cardiac death, non-fatal myocardial infarction (MI), stent thrombosis, stroke and PLATO ('PLATelet inhibition and patient Outcomes') major bleeding at 1 month [14].

\section{Study design}

This is a prospective, randomized, single blind, blinded endpoint evaluation, multicenter trial with a $2 \times 2$ factorial design. The study algorithm is shown in Figure 1. After enrollment and index PCI procedure, clinical follow-up will occur at 1, 3, 12 months and yearly up to 3 years after intervention. Follow-ups will be conducted as telephone contacts or office visits. Unless clinically necessary, there will be no angiographic follow-up until 12 months post PCI, the timepoint for the primary endpoint of the stent comparison. In a subset of patients angiographic follow-up will be recommended at 13 months post PCI. In another subgroup of patients, clopidogrel on-treatment platelet reactivity will be measured using the VerifyNow P2Y12 assay at baseline PCI and at 1-month follow-up. This study is an investigator-initiated clinical trial with grant support from two sources, the Ministry of Health, Welfare, and Family Affairs of the Republic of Korea, and Boston Scientific Korea. Other than providing financial support, Boston Scientific was not involved with the protocol development or the study process, including site selection, management, and data collection and analysis. The authors are solely responsible for the design and conduct of this study, all study analyses, the drafting and editing of the paper and its final contents.

\section{Study population}

Patients that are at least 18 years of age who show on coronary angiogram to have significant coronary artery or graft stenosis and meet all of the inclusion and exclusion criteria (Additional file 1: Table S1) are eligible for this study. This will be an 'all-comers' study, with no angiographic exclusion criteria in order to mimic real world clinical practice and will include the likes of multivessel stenting, left main stenting, chronic total occlusion intervention, bifurcation stenting, saphenous vein graft stenting, previous stent restenosis, and so on. The major exclusion criteria for study enrollment will be known hypersensitivity or contraindication to heparin, aspirin, clopidogrel, cilostazol, everolimus, zotarolimus, or contrast media, systemic (intravenous) us of everolimus or zotarolimus within 12 months, females of childbearing potential, 


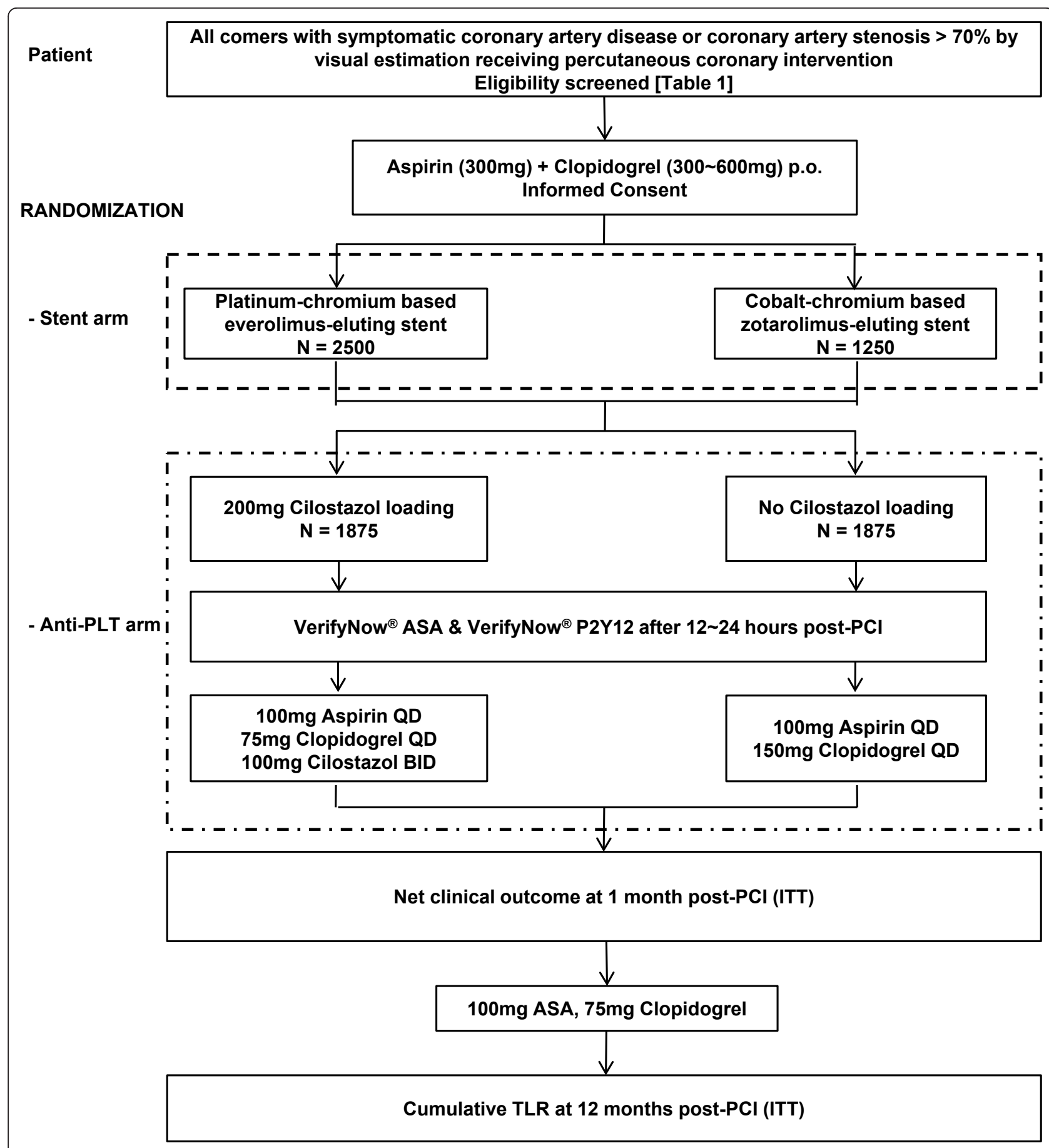

Figure 1 Study algorithm.

unless a recent pregnancy test is negative, a history of bleeding diathesis, known coagulopathy (including heparin-induced thrombocytopenia), abnormal hemogram (hemoglobin $<10 \mathrm{~g} / \mathrm{dl}$ or platelet count $<100,000$ cells $/ \mu \mathrm{l}$ ) or will refuse blood transfusions, patients with severe left ventricular systolic dysfunction (left ventricular ejection fraction $<25 \%$ ), those with cardiogenic shock, gastrointestinal or genitourinary bleeding within the prior 3 months, or major surgery within 2 months, and symptomatic heart failure. The patients that agree to participate in the study and give written informed consent, will be randomized 2:1 to either (a) PtCr-EES or (b) CoCr-ZES, and 1:1 to either (a) TAT or (b) DDAT $(2 \times 2$ design). A total of 3,750 patients plan to be enrolled from 40 high-volume 
hospitals in Korea, the names and investigators of which are listed in Additional file 2: Appendix A.

\section{Interventions and study device, drug}

PCI will be performed with the standard technique and device, that is, catheter, guidewire and balloon catheter. The decision to predilate the lesion, use glycoprotein IIb/ IIIa inhibitors and dilate the stent adjunctively will be up to the operator's discretion. The Promus Element stent is available in diameters of $2.25,2.5,2.75,3.0,3.5$ and 4.0 with lengths of $8,12,16,20,24,28,32$, and $38 \mathrm{~mm}$ (32 and $38 \mathrm{~mm}$ lengths not available for 2.25 and $2.5 \mathrm{~mm}$ diameters). The Endeavor Resolute stent is available in diameters of 2.5, 2.75, 3.0, 3.5 and 4.0, with lengths of 12, 15, 18, 24, 30 and $38 \mathrm{~mm}$ (except for $2.5 \mathrm{~mm}$ stents which are available as $14 \mathrm{~mm}$ length instead of $15 \mathrm{~mm}$, and $38 \mathrm{~mm}$ lengths not available for 2.5 and $2.75 \mathrm{~mm}$ diameters). It will be recommended that all diseased coronary or graft lesions that are the targets of intervention be fully covered by the stent, with non-diseased tissue at each end of the stent. In cases of long lesions that cannot be fully covered by one stent, stent overlap of approximately $1 \mathrm{~mm}$ to 4 $\mathrm{mm}$ will be recommended per manufacturer's instruction for use (IFU). It will be recommended that the allocated stent be implanted in all lesions treated in the same patient. However, other stents may be used in case of device failure, or situations where the operator decides that it is in the best interest of the patient to do so. The use of intravascular ultrasound (IVUS) or optical coherence tomography (OCT) to guide in the procedure will also be up to the operator's discretion.

All patients will receive approximately 300 to $600 \mathrm{mg}$ of clopidogrel and $300 \mathrm{mg}$ of aspirin loading before the procedure. The patients randomized to the TAT group will receive an additional loading of $200 \mathrm{mg}$ cilostazol (Otsuka, Korea) followed by $100 \mathrm{mg}$ twice a day maintenance. Those randomized to the DDAT group will receive $150 \mathrm{mg}$ of clopidogrel maintenance.

\section{Outcome measures}

There are two primary endpoints in this study. The primary endpoint of the trial for the stent comparison will be TLF, defined as a composite of cardiac death, target vessel-related non-fatal MI and ischemia-driven target lesion revascularization (TLR) at 12 months. The primary endpoint for the antiplatelet regimen comparison will be net clinical outcome, defined as a composite of cardiac death, non-fatal MI, stent thrombosis, stroke and PLATO major bleeding at 1 month [14]. The individual component definitions appear in Additional file 2: Appendix B. Stent thrombosis will be adjudicated according to the definitions of the Academic Research Consortium [15]. All endpoints will be analyzed principally on an intention-to-treat basis.
Secondary endpoints of the study will include all of the individual components of the primary endpoint. In addition, all death, ischemia-driven target vessel revascularization (TVR), target vessel failure (TVF), acute success (device, procedure) will be included as secondary endpoints. In the subgroup of patients that receive 13-month angiographic follow-up, both stents will also be analyzed using quantitative coronary angiography (QCA) for late luminal loss, percentage diameter stenosis, IVUS for percentage neointimal volume, or OCT for percentage neointimal coverage. In another subgroup of patients with on-treatment platelet reactivity (OPR) measurement, OPR will be compared between the two antiplatelet regimens, and according to genotype status. The effect of OPR on clinical outcome will also be analyzed.

\section{Statistical considerations Sample size calculations}

To test the first hypothesis that the PtCr-EES is non-inferior to CoCr-ZES in reducing 12-month cumulative TLF after PCI, we assumed the TLF rate of PtCr-EES and $\mathrm{CoCr}-\mathrm{ZES}$ to be $6.5 \%$, based on the results from previous randomized trials $[1,2,7]$. Using a non-inferiority log-rank design with a non-inferiority margin of hazard ratio 1.5 , sampling ratio of EES:ZES at 2:1, allowing 5\% attrition rate for the 12 months, a total of 3,750 patients would result in a power of at least $80 \%$ power with an one-sided $\alpha$ of $2.5 \%$.

Also, to test the second hypothesis that TAT is noninferior to DDAT regarding 1-month net clinical outcome, we assumed the net clinical outcome rate of TAT and DDAT to be $2.0 \%$ and $3.0 \%$, respectively. The net clinical outcome is defined as a composite of cardiac death, nonfatal MI, stent thrombosis, stroke and PLATO major bleeding at 1 month. With a non-inferiority design, a noninferiority margin of $0.75 \%, 1: 1$ randomization to either groups and allowing for $2.5 \%$ attrition for 1-month clinical follow-up, a total of 3,750 patients would provide a onesided $\alpha$ of $2.5 \%$ and $>90 \%$ power.

\section{Statistical analyses}

All primary and secondary endpoints will be analyzed on an intention-to-treat basis (all patients analyzed as part of their assigned treatment group). The endpoints will also be analyzed both on a per-patient and per-lesion basis, whenever applicable. For patients receiving multivessel $\mathrm{PCI}$, the index lesion analyzed in the per-patient analysis will be determined randomly by a computer prior to QCA analysis. For intent-to-treat analysis, all patients who signed the written informed consent form and are randomized in the study will be included in the analysis sample, regardless of whether or not the correct treatment was administered, or whether crossover occurred. 
The second primary endpoint of 12-month cumulative TLF and 1-month cumulative net clinical outcome will be analyzed by comparing the Kaplan-Meier event rates using the log rank test on an intention-to-treat basis. The null hypothesis will be evaluated using a non-inferiority statistics. The outcomes will also be analyzed according to subgroups defined a priori. These include the following: for comparison of the stent arm, subgroup analysis will be performed according to the lesion length, vessel size, renal dysfunction, multivessel stenting, and presence or absence of diabetes mellitus; for comparison of the antiplatelet arm, subgroup analysis will be performed according to the prescription status of calcium-channel blockers, 3-hydroxy-3methylglutaryl-coenzyme A (HMG-CoA) reductase inhibitors, allocated stent, renal dysfunction, multivessel stenting, and the presence or absence of diabetes mellitus. The multiple imputation method will be used to handle missing data.

\section{Trial organization and ethical considerations}

The overall trial organization is summarized in Additional file 2: Appendix C. The trial was designed by the principal investigators and the executive committee. Besides the executive committee, the steering committee, data safety monitoring board, and the clinical event adjudication committee will be involved in the execution, administration, and supervision of the trial. The specific role and information regarding each of the committees appear in Additional file 2: Appendix C. The study will be sponsored by the Seoul National University Hospital (SNUH) Cardiovascular Clinical Research Center (CCRC) and the data will be managed by an independent contract research organization, Dream CIS Inc. Dream CIS will be responsible for the development of a web-based randomization system, maintenance of the web-based case report form, and data collection from individual sites. Site monitoring will be performed by the CCRC of SNUH. The trial monitors will review the documents of at least $30 \%$ of the patients enrolled from each participating center, at appropriate intervals, for accuracy and completeness and to ensure compliance with the protocol. The trial monitor will be able to inspect all documents and required records that are maintained by the individual investigator and site, including medical records (office, clinic, or hospital) for the subjects in this trial. The study will be performed in accordance with the Declaration of Helsinki. Before participation of the study, each patient will be given full information, that is, purpose, methods, rights, duties and possible risk/benefits of the study in plain, lay language. Written, informed consent is a prerequisite to the participation in the study.

\section{Ethical approval}

This study was approved by the institutional review board at Seoul National University Hospital (D-1005-001-068) and by the local ethical committee at each participating hospital. The protocol of the trial has been registered at http://www.clinicaltrials.gov (NCT01267734).

\section{Discussion}

\section{EES and ZES in clinical practice}

The second-generation CoCr-EES (Xience V, Promus) has been shown to be either comparable or better than its first-generation counterparts. In large scale randomized trials against paclitaxel-eluting stents (PES), such as the SPIRIT IV and COMPARE trials, it was superior to PES with regard to both efficacy and safety where the primary clinical endpoints were reduced by $38 \%$ and $31 \%$, respectively $[1,2]$, which has now been reaffirmed in a meta-analysis [16]. In randomized trials and meta-analysis comparing CoCr-EES and SES, such as the EXCELLENT, ISAR-TEST 4, SORT-OUT IV, and so on, CoCr-EES showed similar efficacy with slight trend toward superior safety [4-6]. The next addition to the second-generation DES market has been the CoCr-ZES (Endeavor Resolute), which showed equivalent outcome compared with the CoCr-EES in the RESOLUTE All-Comers randomized trial [7]. Because of the all-comers population that was studied in this trial, data were available regarding to the performance of the second-generation stents in complex lesions such as coronary total occlusions, bifurcation lesions, saphenous vein grafts, in-stent restenosis, unprotected left main lesions, multivessel stenting, and so on, which constituted approximately two-thirds of the lesions treated in the trial [17]. In this complex subgroup, there were no significant differences between the two DES devices but the TLF rate at 1 year numerically favored CoCr-ZES. Both of these second-generation DES are based on a cobalt chromium alloy stent. Most recently, a newly developed stent alloy, the platinum chromium alloy, was incorporated with everolimus to create the PtCr-EES, the Promus Element stent (Boston Scientific). In the only randomized trial to date with the PtCr-EES, the PLATINUM trial, where it was compared against CoCr-EES in a select group of patients with various angiographic exclusions [8], PtCr-EES was non-inferior to CoCr-EES for the primary endpoint of TLF, with insignificant differences in measures of safety and efficacy through 1 year. Both stents showed low event rates at 1 year (TLF rate: $3.4 \%$ vs $2.9 \%$ for PtCr-EES vs CoCr-EES, $P=0.60$ ). However the PtCrEES has not been studied randomly in a broader population of patients as was enrolled in the RESOLUTE All-Comers trial, which better reflects the day-to-day clinical practice in most centers of coronary intervention. The non-inferiority margin of $3.25 \%$ may seem large given that the estimated rate of the primary endpoint is $6.5 \%$. However, in the RESOLUTE All-Comers trial and the PLATINUM trial, well known previous studies incorporating the non-inferiority design regarding stent comparisons, a 
non-inferiority margin of $3.5 \%$ has been used $[7,8]$. In addition, because of the paucity of the data on PtCr-EES, the sampling ratio was set at 2:1 to maximize the number of patients randomized to the PtCr-EES arm.

\section{Antiplatelet regimen after $\mathrm{PCI}$}

Antiplatelet therapy is one of the most important components of successful outcome after PCI. High on-treatment platelet reactivity (HOPR) has been shown to be an independent predictor of thrombotic outcomes [9-12]. In particular, the first month after PCI is the most important period to inhibit platelet function to prevent thrombotic events, since the greatest association between heightened platelet reactivity and thrombotic outcome is seen in the first month post PCI [18]. In Korea, where the HOPR rate of the general population receiving $\mathrm{PCI}$ is above $50 \%$ and frequency of the cytochrome P450 2C19 (CYP2C19) lossof-function (LOF) allele is greater than 60\% [12,19-21], we may need increased platelet inhibition during this critical period.

To increase platelet inhibition after PCI, the approach is slightly different between Western and Asian doctors. Before prasugrel and ticagrelor, most Western doctors prescribed double dose of clopidogrel in high-risk settings. However, in Asia and in particular in Korea, doctors prefer addition of cilostazol on conventional dual antiplatelet therapy (DAPT) to doubling the dose of clopidogrel. In the CURRENT-OASIS 7 trial, a 1-week duration of doubling the dose of clopidogrel was shown to improve outcome at 1 month compared with conventional dose in ACS patients undergoing PCI [13]. The basis of adding cilostazol in Korea comes from pharmacodynamic studies from our group and others, which have shown that TAT is superior to DDAT with regard to inhibition of platelet reactivity in patients with high platelet reactivity [22], and in carriers of the CYP2C19 LOF allele [23]. In the DECLARE-Diabetes, and DECLARE-Long studies, TAT was superior to conventional DAPT regarding inhibition of neointima formation and significantly reduced rates of clinically driven TLR $[24,25]$. In the CILON-T trial, which was underpowered to show differences in clinical outcome, there were no significant difference between TAT and conventional DAPT although TAT more profoundly reduced OPR [26]. However in the post hoc analysis, we showed that there was a significant trend toward worse outcome in those with high OPR suggesting that cilostazol may have some beneficial effects in higher-risk populations.

Because of the paucity of sound clinical data regarding the use of TAT based on randomized clinical trials, and in light of the abundant use of cilostazol as a third agent in post-PCI management in Korea, a large scale randomized controlled trial (RCT) to confirm the safety and efficacy of TAT is needed at present. After initiation of the 'Harmonizing Optimal Strategy for Treatment of coronary artery stenosis - sAfety \& effectiveneSS of drugelUting stents \& antiplatelet REgimen' (HOST-ASSURE) trial, we anticipate enrollment within 1 year. The large scale and all-comers design of the HOST-ASSURE trial will provide important insight into two issues in interventional cardiology. First, it will test whether the newest DES platform, PtCr-EES will be as effective and safe as CoCr-ZES in preventing TLF. Second, it will also address the issue of whether TAT is non-inferior to DDAT in reducing net clinical outcome within the first month post PCI.

\section{Trial status}

The HOST-ASSURE Trial is ongoing. Patient recruitment has been completed and follow-up is being conducted.

\section{Additional material}

Additional file 1: Table S1: Enrollment criteria.

Additional file 2: Appendices A-C. Appendix A: participating highvolume hospitals in Korea. Appendix B: endpoint definitions. Bleeding/ hemorrhagic complications. Appendix C: trial organization.

\section{Acknowledgements}

We thank Tae-Eun Kim, RN for her devotion and efforts in initiating the trial. $\mathrm{H}$-SK is also a professor of Molecular Medicine and Biopharmaceuticals Sciences, Seoul National University, sponsored by World Class University (WCU) program from the Ministry of Education and Science, Korea. This study was supported by a grant from the Clinical Research Center for Ischemic Heart Disease, Korea Healthcare Technology R\&D Project, Ministry of Health and Welfare, Republic of Korea (A102065), and a grant from the Innovative Research Institute for Cell Therapy, Seoul National University Hospital (A062260), sponsored by the Ministry of Health and Welfare, Republic of Korea. The authors also received an unrestricted grant from Boston Scientific Korea. The funding sources had no role in study design or the writing of this manuscript.

\section{Author details}

'Department of Internal Medicine, Cardiovascular Center, Seoul National University Hospital, 101 Daehang-no, Seoul 110-744, South Korea. ${ }^{2}$ Dankook University Hospital, Cheonan, South Korea. ${ }^{3}$ Busan National University Hospital, Busan, South Korea. ${ }^{4}$ Presbyterian Medical Center, Jeonju, South Korea. ${ }^{5}$ Uijeongbu St. Mary's Hospital, Uijeongbu, South Korea. ${ }^{6}$ Ulsan University Hospital, Ulsan, South Korea. ${ }^{7}$ Samsung Changwon Hospital, Changwon, South Korea. ${ }^{8}$ Chonnam National University Hospital, Gwangju, South Korea. ${ }^{9}$ Boramae Medical Center, Seoul, South Korea. ${ }^{10}$ Chungbuk National University Hospital, Cheongju, South Korea. ${ }^{11}$ Wonju Christian Hospital, Wonju, South Korea. ${ }^{12}$ Inje University Ilsan Paik Hospital, Goyang, South Korea. ${ }^{13}$ Dong-A Medical Center, Busan, South Korea. ${ }^{14}$ St. Vincent's Hospital, Suwon, South Korea. ${ }^{15}$ Gangnam Severance Hospital, Seoul, South Korea. ${ }^{16}$ Seoul National University Bundang Hospital, Seongnam, South Korea.

\section{Authors' contributions}

KWP and B-EP contributed to the initial conception, study design, data, acquisition, and wrote the manuscript, S-HK, J-JP, and S-PL contributed to the study design, data acquisition, data interpretation, and drafting of the manuscript. KSC, JYR, H-KJ, ESS, and JHO contributed to patient enrollment, critical reading and revision of the manuscript. $\mathrm{M}-\mathrm{HJ}, \mathrm{SK}, \mathrm{K}-\mathrm{KH}$, and J-HY contributed to the study design, and drafting of the protocol. SYL, T-HP, 
KWM, and H-MK contributed to patient enrollment, data acquisition, and critical reading and revision of the manuscript. I-HC and $\mathrm{H}$-SK contributed to the initial conception of the study, protocol development, writing of the manuscript and final approval of the submitted version. KWP and B-EP contributed equally. All authors read and approved the final manuscript.

\section{Competing interests}

The authors declare that they have no competing interests.

Received: 26 December 2011 Accepted: 31 March 2012 Published: 31 March 2012

\section{References}

1. Kedhi E, Joesoef KS, McFadden E, Wassing J, van Mieghem C, Goedhart D, Smits PC: Second-generation everolimus-eluting and paclitaxel-eluting stents in real-life practice (COMPARE): a randomised trial. Lancet 2010, 375:201-209.

2. Stone GW, Rizvi A, Newman W, Mastali K, Wang JC, Caputo R, Doostzadeh J, Cao S, Simonton CA, Sudhir K, Lansky AJ, Cutlip DE, Kereiakes DJ, SPIRIT IV Investigators: Everolimus-eluting versus paclitaxeleluting stents in coronary artery disease. N Engl J Med 2010, 362:1663-1674.

3. Takagi H, Umemoto T: An updated meta-analysis of randomized controlled trials of everolimus- versus paclitaxel-eluting stents. Int $J$ Cardiol 2011, 151:354-355.

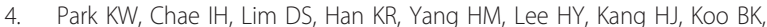
Ahn T, Yoon JH, Jeong MH, Hong TJ, Chung WY, Jo SH, Choi YJ, Hur SH, Kwon HM, Jeon DW, Kim BO, Park SH, Lee NH, Jeon HK, Gwon HC, Jang YS, Kim HS: Everolimus-eluting versus sirolimus-eluting stents in patients undergoing percutaneous coronary intervention: the EXCELLENT (Efficacy of Xience/Promus Versus Cypher to Reduce Late Loss After Stenting) randomized trial. J Am Coll Cardiol 2011, 58:1844-1854.

5. Byrne RA, Kastrati A, Massberg S, Wieczorek A, Laugwitz KL, Hadamitzky M, Schulz S, Pache J, Fusaro M, Hausleiter J, Schömig A, Mehilli J, ISAR-TEST 4 Investigators: Biodegradable polymer versus permanent polymer drugeluting stents and everolimus- versus sirolimus-eluting stents in patients with coronary artery disease: 3-year outcomes from a randomized clinical trial. J Am Coll Cardiol 2011, 58:1325-1331.

6. de Waha A, Dibra A, Byrne RA, Ndrepepa G, Mehilli J, Fusaro M, Laugwitz KL, Massberg S, Schömig A, Kastrati A: Everolimus-eluting versus sirolimus-eluting stents: a meta-analysis of randomized trials. Circ Cardiovasc Interv 2011, 4:371-377.

7. Serruys PW, Silber S, Garg S, van Geuns RJ, Richardt G, Buszman PE, Kelbaek H, van Boven AJ, Hofma SH, Linke A, Klauss V, Wijns W, Macaya C, Garot P, DiMario C, Manoharan G, Kornowski R, Ischinger T, Bartorelli A, Ronden J, Bressers M, Gobbens P, Negoita M, van Leeuwen F, Windecker S: Comparison of zotarolimus-eluting and everolimus-eluting coronary stents. N Engl J Med 2010, 363:136-146.

8. Stone GW, Teirstein PS, Meredith IT, Farah B, Dubois CL, Feldman RL, Dens J, Hagiwara N, Allocco DJ, Dawkins KD, PLATINUM Trial Investigators: A prospective, randomized evaluation of a novel everolimus-eluting coronary stent: the PLATINUM (a Prospective, Randomized, Multicenter Trial to Assess an Everolimus-Eluting Coronary Stent System [PROMUS Element] for the Treatment of Up to Two de Novo Coronary Artery Lesions) trial. J Am Coll Cardiol 2011, 57:1700-1708.

9. Price MJ, Endemann S, Gollapudi RR, Valencia R, Stinis CT, Levisay JP, Ernst A, Sawhney NS, Schatz RA, Teirstein PS: Prognostic significance of post-clopidogrel platelet reactivity assessed by a point-of-care assay on thrombotic events after drug-eluting stent implantation. Eur Heart J 2008, 29:992-1000.

10. Patti G, Nusca A, Mangiacapra F, Gatto L, D'Ambrosio A, Di Sciascio G: Point-of-care measurement of clopidogrel responsiveness predicts clinical outcome in patients undergoing percutaneous coronary intervention results of the ARMYDA-PRO (Antiplatelet therapy for Reduction of MYocardial Damage during Angioplasty-Platelet Reactivity Predicts Outcome) study. J Am Coll Cardiol 2008, 52:1128-1133.

11. Marcucci R, Gori AM, Paniccia R, Giusti B, Valente S, Giglioli C, Buonamici P, Antoniucci D, Abbate R, Gensini GF: Cardiovascular death and nonfatal myocardial infarction in acute coronary syndrome patients receiving coronary stenting are predicted by residual platelet reactivity to ADP detected by a point-of-care assay: a 12-month follow-up. Circulation 2009, 119:237-242

12. Park KW, Jeon KH, Kang SH, Oh IY, Cho HJ, Lee HY, Kang HJ, Park SK, Koo BK, Oh BH, Park YB, Kim HS: Clinical outcomes of high on-treatment platelet reactivity in Koreans receiving elective percutaneous coronary intervention (from results of the CROSS VERIFY study). Am J Cardiol 2011, 108:1556-1563.

13. Mehta SR, Tanguay JF, Eikelboom JW, Jolly SS, Joyner CD, Granger CB, Faxon DP, Rupprecht HJ, Budaj A, Avezum A, Widimsky P, Steg PG, Bassand JP, Montalescot G, Macaya C, Di Pasquale G, Niemela K, Ajani AE, White HD, Chrolavicius S, Gao P, Fox KA, Yusuf S, CURRENT-OASIS 7 trial investigators: Double-dose versus standard-dose clopidogrel and highdose versus low-dose aspirin in individuals undergoing percutaneous coronary intervention for acute coronary syndromes (CURRENT-OASIS 7): a randomised factorial trial. Lancet 2010, 376:1233-1243.

14. James S, Akerblom A, Cannon CP, Emanuelsson H, Husted S, Katus H, Skene A, Steg PG, Storey RF, Harrington R, Becker R, Wallentin L: Comparison of ticagrelor, the first reversible oral P2Y(12) receptor antagonist, with clopidogrel in patients with acute coronary syndromes: rationale, design, and baseline characteristics of the PLATelet inhibition and patient Outcomes (PLATO) trial. Am Heart J 2009, 157:599-605.

15. Cutlip DE, Windecker S, Mehran R, Boam A, Cohen DJ, van Es GA, Steg PG, Morel MA, Mauri L, Vranckx P, McFadden E, Lansky A, Hamon M, Krucoff MW, Serruys PW, Academic Research Consortium: Clinical end points in coronary stent trials: a case for standardized definitions. Circulation 2007, 115:2344-2351.

16. Baber U, Mehran R, Sharma SK, Brar S, Yu J, Suh JW, Kim HS, Park SJ, Kastrati A, de Waha A, Krishnan P, Moreno P, Sweeny J, Kim MC, Suleman J, Pyo R, Wiley J, Kovacic J, Kini AS, Dangas GD: Impact of the everolimuseluting stent on stent thrombosis a meta-analysis of 13 randomized trials. J Am Coll Cardiol 2011, 58:1569-1577.

17. Stefanini GG, Serruys PW, Silber S, Khattab AA, van Geuns RJ, Richardt G, Buszman PE, Kelbæk H, van Boven AJ, Hofma SH, Linke A, Klauss V, Wijns W, Macaya C, Garot P, Di Mario C, Manoharan G, Kornowski R, Ischinger T, Bartorelli AL, Gobbens P, Windecker S: The impact of patient and lesion complexity on clinical and angiographic outcomes after revascularization with zotarolimus- and everolimus-eluting stents: a substudy of the RESOLUTE All Comers trial (a randomized comparison of a zotarolimus-eluting stent with an everolimus-eluting stent for percutaneous coronary intervention). J Am Coll Cardiol 2011, 57:2221-2232.

18. Sibbing D, Braun S, Morath T, Mehilli J, Vogt W, Schömig A, Kastrati A, von Beckerath $\mathrm{N}$ : Platelet reactivity after clopidogrel treatment assessed with point-of-care analysis and early drug-eluting stent thrombosis. J Am Coll Cardiol 2009, 53:849-856.

19. Hwang SJ, Jeong YH, Kim IS, Koh JS, Kang MK, Park Y, Kwak CH, Hwang JY: The cytochrome $2 \mathrm{C} 19 * 2$ and $* 3$ alleles attenuate response to clopidogrel similarly in East Asian patients undergoing elective percutaneous coronary intervention. Thromb Res 2011, 127:23-28.

20. Oh IY, Park KW, Kang SH, Park JJ, Na SH, Kang HJ, Koo BK, Jeong YH, Hwang JY, Kwak CH, Park Y, Hwang SJ, Ko YG, Shin DJ, Jang Y, Kim HS: Association of cytochrome P450 2 C19*2 polymorphism with clopidogrel response variability and cardiovascular events in Koreans treated with drug-eluting stents. Heart 2012, 98:139-144.

21. Park KW, Park JJ, Jeon KH, Kang SH, Oh IY, Yang HM, Cho HJ, Lee HY, Kang HJ, Koo BK, Oh BH, Park YB, Kim HS: Clinical predictors of high posttreatment platelet reactivity to clopidogrel in Koreans. Cardiovasc Ther 2012, 30:5-11.

22. Jeong YH, Lee SW, Choi BR, Kim IS, Seo MK, Kwak CH, Hwang JY, Park SW: Randomized comparison of adjunctive cilostazol versus high maintenance dose clopidogrel in patients with high post-treatment platelet reactivity: results of the ACCEL-RESISTANCE (Adjunctive Cilostazol Versus High Maintenance Dose Clopidogrel in Patients With Clopidogrel Resistance) randomized study. J Am Coll Cardiol 2009, 53:1101-1109.

23. Park KW, Park JJ, Lee SP, Oh IY, Suh JW, Yang HM, Lee HY, Kang HJ, Cho YS, Koo BK, Youn TJ, Chae IH, Choi DJ, Oh BH, Park YB, Kim HS: Cilostazol attenuates on-treatment platelet reactivity in patients with CYP2C19 loss of function alleles receiving dual antiplatelet therapy: a genetic substudy of the CILON-T randomised controlled trial. Heart 2011, 97:641-647. 
24. Lee SW, Park SW, Kim YH, Yun SC, Park DW, Lee CW, Hong MK, Kim HS, Ko JK, Park JH, Lee JH, Choi SW, Seong IW, Cho YH, Lee NH, Kim JH, Chun KJ, Park SJ: Drug-eluting stenting followed by cilostazol treatment reduces late restenosis in patients with diabetes mellitus the DECLAREDIABETES Trial (A Randomized Comparison of Triple Antiplatelet Therapy with Dual Antiplatelet Therapy After Drug-Eluting Stent Implantation in Diabetic Patients). J Am Coll Cardiol 2008, 51:1181-1187.

25. Lee SW, Park SW, Kim YH, Yun SC, Park DW, Lee CW, Kang SJ, Park SJ, Lee JH, Choi SW, Seong IW, Lee NH, Cho YH, Shin WY, Lee SJ, Lee SW, Hyon MS, Bang DW, Choi YJ, Kim HS, Lee BK, Lee K, Park HK, Park CB, Lee SG, Kim MK, Park KH, Park WJ, DECLARE-LONG II Study Investigators: A randomized, double-blind, multicenter comparison study of triple antiplatelet therapy with dual antiplatelet therapy to reduce restenosis after drug-eluting stent implantation in long coronary lesions: results from the DECLARE-LONG II (Drug-Eluting Stenting Followed by Cilostazol Treatment Reduces Late Restenosis in Patients with Long Coronary Lesions) trial. J Am Coll Cardiol 2011, 57:1264-1270.

26. Suh JW, Lee SP, Park KW, Lee HY, Kang HJ, Koo BK, Cho YS, Youn TJ, Chae IH, Choi DJ, Rha SW, Bae JH, Kwon TG, Bae JW, Cho MC, Kim HS: Multicenter randomized trial evaluating the efficacy of cilostazol on ischemic vascular complications after drug-eluting stent implantation for coronary heart disease: results of the CILON-T (influence of CILostazolbased triple antiplatelet therapy $\mathrm{ON}$ ischemic complication after drugeluting stenT implantation) trial. J Am Coll Cardiol 2011, 57:280-289.

doi:10.1186/1745-6215-13-29

Cite this article as: Park et al:: The 'Harmonizing Optimal Strategy for Treatment of coronary artery stenosis - sAfety \& effectiveneSS of drugelUting stents \& antiplatelet REgimen' (HOST-ASSURE) trial: study protocol for a randomized controlled trial. Trials 2012 13:29.

\section{Submit your next manuscript to BioMed Central and take full advantage of:}

- Convenient online submission

- Thorough peer review

- No space constraints or color figure charges

- Immediate publication on acceptance

- Inclusion in PubMed, CAS, Scopus and Google Scholar

- Research which is freely available for redistribution

Submit your manuscript at www.biomedcentral.com/submit 